\title{
Left Ventricular Contractility in Extremely Premature Infants in the First Day and Response to Inotropes
}

\author{
DAVID A. OSBORN, NICK EVANS, AND MARTIN KLUCKOW
}

\begin{abstract}
RPA Newborn Care [D.A.O., N.E.], Royal Prince Alfred Hospital, Camperdown, NSW 2050, Australia; Department of Neonatology [M.K.], Royal North Shore Hospital, St. Leonards, NSW 2065, Australia; The University of Sydney [D.A.O., N.E., M.K.], Sydney 2006, Australia
\end{abstract}

\begin{abstract}
The aim was to assess myocardial contractility in infants born $<30$ wk gestation developing low systemic blood flow (SBF) in the first day, and the effect of dobutamine versus dopamine. Superior vena cava (SVC) flow was used as a measure of SBF at 3, 10 , and $24 \mathrm{~h}(n=106)$. Infants with low SVC flow randomized to dopamine or dobutamine. Myocardial contractility was determined by the relationship between left ventricular (LV) mean velocity of circumferential fiber shortening $(\mathrm{mVcfs})$ and wall stress. Infants who developed low SVC flow had significantly worse myocardial contractility at $3 \mathrm{~h}$, but not $10 \mathrm{~h}$. At $24 \mathrm{~h}$, low-flow infants had lower than expected $\mathrm{mVcfs}$ for any given LV stress. In 37 infants randomized to inotrope, there was no significant difference in contractility at 10 $\mu \mathrm{g} / \mathrm{kg} / \mathrm{min}$. At $20 \mu \mathrm{g} / \mathrm{kg} / \mathrm{min}(n=21)$, dopamine increased whereas dobutamine decreased LV stress. Infants on dobutamine had significantly lower than expected $\mathrm{mV}$ cfs for any given LV stress compared with infants on dopamine. Contractility was not improved by either inotrope at either dose. In conclusion, infants developing low SVC flow in the first day have worse myocardial contractility at $3 \mathrm{~h}$. Neither inotrope increased contractility, but dopamine increased LV stress at $20 \mu \mathrm{g} / \mathrm{kg} / \mathrm{min}$. (Pediatr Res 61: 335-340, 2007)
\end{abstract}

$\mathrm{E}$ xtremely preterm infants with low brain and upper body blood flow, as measured by SVC flow, in the first day are at increased risk of late peri/intraventricular hemorrhage $(1,2)$, mortality, and subsequent neurodevelopmental impairment (3). Low SVC flow was associated with infants born at lower gestation, with a higher MAP in the first $12 \mathrm{~h}$ and a larger diameter DA at $5 \mathrm{~h}$ of age (1). Although infants with low SVC flow frequently had normal BP, they had significantly higher calculated UBVR compared with infants with normal flows. However, calculated vascular resistance is not a direct measure of LV afterload. LV stress is affected by LV dimensions, which are affected by preload, and LV wall thickness $(4,5)$.

Although LV shortening fraction has been reported to be reduced in shocked and acidotic preterm infants (6), this measure of LV performance does not take preload or afterload conditions into account and has been reported to be unreliable in preterm infants (7). In contrast, the relationship between LV $\mathrm{mV} c f s$ and LV wall stress (LV stress) has been used as a

Received September 6, 2006; accepted October 19, 2006

Correspondence: David Osborn, M.M., FRACP, PhD, RPA Newborn Care, Royal Prince Alfred Hospital, Missenden Rd, Camperdown, NSW 2050, Australia; e-mail: david.osborn@email.cs.nsw.gov.au

This work was supported by the Australian Government National Health and Medical Research Council (NH \& MRC) and the North Shore Heart Research Foundation.

DOI: 10.1203/pdr.0b013e318030d1e1 preload independent measure of LV contractility that takes into account afterload conditions. Myocardial contraction velocity will fall as afterload increases. A steeper negative slope of the regression line of the relationship indicates a more rapidly reducing $\mathrm{mVcfs}$ in response to increasing $\mathrm{LV}$ stress, or reduced myocardial contractility $(4,8)$. Preterm infants have been documented to have reduced LV contractility in the first days after birth compared with term infants (9), although the relationship to low blood flow states has not been reported. In addition, the effects on myocardial contractility of commonly used inotropes in preterm infants have not been measured in infants with low flow in the first day.

The aim of this study was 1) to examine the relationship between $\mathrm{LV} \mathrm{mV}$ cfs and wall stress in very preterm infants in the first day with normal and low SVC flows, and 2) to examine the effects of dobutamine and dopamine on this relationship in very preterm infants with low SVC flow in the first day.

\section{METHODS}

Cohort study. The study was nested in a two center, prospective cohort study of 128 infants born $<30$ wk gestation, the clinical outcomes and blood flow findings of which have been reported previously $(2,10,11)$. Infants were eligible for inclusion if born $<30 \mathrm{wk}$ gestation, were $<12 \mathrm{~h}$ after birth, and there was informed parental consent. Infants were excluded if a major congenital or cardiac abnormality was identified, considered by the attending clinician to be nonviable, or if inotrope or indomethacin had been given before enrollment. This report is restricted to 106 infants with an intra-arterial line and who had measurements of LV function performed in the first $24 \mathrm{~h}$. The study was carried out in the Royal Prince Alfred and Royal North Shore Hospital Neonatal Intensive Care Units, Sydney, Australia, between October 1998 and December 1999. The ethics committees of Central Sydney and Northern Sydney Area Health Services approved the study.

Echocardiography was performed on 122 infants at $3 \mathrm{~h}, 126$ infants at 10 $\mathrm{h}$, and 119 infants at $24 \mathrm{~h}$ after birth. Invasive BP monitoring was required for calculation of LV wall stress but was unavailable for 25 infants at $3 \mathrm{~h}, 19$ infants at $10 \mathrm{~h}$ and 20 infants at $24 \mathrm{~h}$. Measurements of LV function including mVcfs and LV wall stress were available for a total of 106 infants in the first $24 \mathrm{~h}$, including 94 at $3 \mathrm{~h}, 104$ at $10 \mathrm{~h}$, and 97 at $24 \mathrm{~h}$. Technical difficulties with echocardiography or videotape recordings accounted for lost measurements on 3 infants at 3 and $10 \mathrm{~h}$ and 2 infants at $24 \mathrm{~h}$.

Randomized trial of dobutamine versus dopamine. Forty two infants with low SVC flow $(<41 \mathrm{~mL} / \mathrm{kg} / \mathrm{min})$ were enrolled in a blinded randomized trial of volume and dobutamine versus volume and dopamine, from which the effects on blood flow and clinical outcomes have been reported previously (11). After normal saline, $10 \mathrm{~mL} / \mathrm{kg}$, infants were randomized to dobutamine

Abbreviations: BP, blood pressure; DA, ductus arteriosus; LV stress, left ventricular wall stress; MAP, mean airway pressure; $\mathbf{m V c f s , ~ m e a n ~ v e l o c i t y ~ o f ~}$ circumferential fiber shortening; RVO, right ventricular output; SBF, systemic blood flow; SVC flow, superior vena cava flow; UBVR, upper body vascular resistance 
or dopamine, initially at 10 , increasing to $20 \mu \mathrm{g} / \mathrm{kg} / \mathrm{min}$ if SVC flows failed to be maintained $>40 \mathrm{~mL} / \mathrm{kg} / \mathrm{min}$ in the first $24 \mathrm{~h}$. Invasive arterial monitoring using umbilical or peripheral arterial catheters was available in 37 of the 42 infants enrolled. Measurements of myocardial contractility were available for 21 of 22 infants randomized to volume and dobutamine, and 16 of 20 infants randomized to volume and dopamine.

Physiologic and echocardiographic measurements. Physiologic measurements including heart rate, mean BP, and MAP were taken immediately before echocardiography. All BP measurements were taken from an umbilical arterial or peripheral arterial catheter. Mean airway pressure was recorded from the Dräger Babylog 8000 ventilator measured pressure.

Echocardiographic monitoring was performed routinely at 3, 10, and $24 \mathrm{~h}$ (cohort study). Echocardiography was also performed on infants enrolled in the trial of volume and inotrope immediately before and after normal saline, and immediately before and $30 \mathrm{~min}$ after commencement of inotrope, or change in dose of inotrope. All measurements were performed blind to treatment allocation. An Acuson (Mountain View, CA) 128/XP10 ultrasound scanner was used with a $7 \mathrm{MHz}$ vector array transducer incorporating colour flow and pulsed wave Doppler. The scan was recorded on to VHS videotape and the measurements then taken from the videotape. Structural normality of the heart was established on the initial scan. All eligible infants had echocardiographic measurements of SVC flow, right ventricular output (RVO), color Doppler DA diameter, mVcfs, and LV stress at 3, 10, and $24 \mathrm{~h}$ after birth. RVO, SVC flow, and DA diameter were measured as previously reported (12-14). Upper body systemic vascular resistance was calculated from BP and SVC flow measurements:

UBVR $[\mathrm{mm} \mathrm{Hg} / \mathrm{mL} / \mathrm{kg} / \mathrm{min}]$

$$
=\text { mean } \mathrm{BP}(\mathrm{mm} \mathrm{Hg}) \div \mathrm{SVC} \text { flow }(\mathrm{mL} / \mathrm{kg} / \mathrm{min}) \text {. }
$$

Left ventricular mean velocity of circumferential fractional shortening (mVcfs) was determined by the method described by Berdjis et al. (15) using following formula:

$$
\mathrm{mVcfs}(\text { circumferences } / \mathrm{s})=(\mathrm{Ced}-\mathrm{Ces}) \div(\mathrm{Ced})(\mathrm{ETc}),
$$

where Ced = end-diastolic circumference; $\mathrm{Ces}=$ end-systolic circumference; and $\mathrm{ETc}=$ left ventricular ejection time corrected for heart rate $[\mathrm{ETc}=$ ET/ $\sqrt{ }$ RR interval]. Ced and Ces were measured by tracing the internal circumference of the left ventricle from a two-dimensional image using a short axis view of the left ventricle at the level of the mitral valve leaflets. ETc and the RR interval were measured form the arterial pulse wave trace.

The LV stress was calculated by the method described by Grossman et al. (16) using the following formula:

$$
\mathrm{LV} \text { stress }=0.34(\text { Des })(\mathrm{ESP}) \div \mathrm{h}[1+(\mathrm{h} / \text { Des })],
$$

where Des $=$ end-systolic diameter calculated by dividing Ces by $\pi$ to minimize errors due to irregularity of the left ventricular shape; ESP = end-systolic pressure; and $\mathrm{h}=$ left ventricular posterior wall thickness. ESP $(\mathrm{mm} \mathrm{Hg})$ was interpreted from the arterial pulse tracing as the pressure at the dicrotic notch. The left ventricular wall thickness (h) was measured from the M-mode short axis view of the left ventricle at the level of the mitral valve leaflets.

Statistics. Data were analyzed using SPPS (SPSS Inc., Chicago, IL). Categorical variables were compared using a two-sided $\chi^{2}$ test or Fisher exact test where appropriate. Continuous variables were compared using a twosample $t$ test for parametric and Mann-Whitney $U$ test for nonparametric variables. Myocardial contractility was assessed by examining the scatter plots of mVcfs versus $\mathrm{LV}$ stress and determining the slope of best fit using two-stage least squares linear regression analysis. Regression analyses were performed comparing infants who developed low SVC flow $(<41 \mathrm{~mL} / \mathrm{kg} /$ $\mathrm{min}$ ) in the first $24 \mathrm{~h}$ to those who maintained SVC flows, and comparing infants who initially received dobutamine to those who received dopamine from before, at 10 and $20 \mu \mathrm{g} / \mathrm{kg} / \mathrm{min}$. A second analysis was performed using regression modeling in SAS exploring for possible interactions between inotrope and dose using a model that combined observations across time periods. This allowed the analyses to determine whether changes in contractility were due to changes in slope or position of the regression lines, representing the difference between inotropes for expected value of $\mathrm{mVcfs}$ for any given value of LV stress. In both sets of analyses, one extreme outlier was excluded. The combined regression analysis model used terms to adjust for inotrope, difference between inotrope, and dose of inotrope allowing for interactions between inotrope and dose. As not all infants had the dose of inotrope increased to $20 \mu \mathrm{g} / \mathrm{kg} / \mathrm{min}$, the final analysis was adjusted for risk factors for failure of response to inotropes including lack of antenatal corticosteroids, gestational age, MAP, and baseline SVC flow (11).
Table 1. Demographic and respiratory data comparing infants maintaining normal ( $\geq 41 \mathrm{~mL} / \mathrm{kg} / \mathrm{min})$ or low $(<41 \mathrm{~mL} / \mathrm{kg} / \mathrm{min})$ SVC flow in first $24 \mathrm{~h}$

\begin{tabular}{lccc}
\hline & $\begin{array}{c}\text { Normal SVC } \\
\text { flow }\end{array}$ & $\begin{array}{c}\text { Low SVC } \\
\text { flow }\end{array}$ & p Value \\
\hline No. & 66 & 40 & \\
Mean gestation, wk (SD) & $27.1(1.7)$ & $25.8(1.8)$ & $<0.001$ \\
Mean birth weight, g (SD) & $999(290)$ & $924(277)$ & 0.2 \\
Birth weight $\leq 10$ th percentile & $9(14 \%)$ & 0 & 0.01 \\
Male & $36(55 \%)$ & $18(45 \%)$ & 0.3 \\
Antenatal steroids & $63(95 \%)$ & $33(83 \%)$ & 0.04 \\
Maternal antihypertensives & $18(27 \%)$ & $1(3 \%)$ & 0.001 \\
Vaginal delivery & $25(38 \%)$ & $21(53 \%)$ & 0.1 \\
Ex utero transfer & $4(6 \%)$ & $8(20 \%)$ & 0.054 \\
Apgar $\leq 4$ at 1 min & $26(39 \%)$ & $22(55 \%)$ & 0.1 \\
Ventilated & $64(97 \%)$ & $40(100 \%)$ & 0.5 \\
Average MAP first 12 h (SD) & $7.6(2.5)$ & $8.7(2.5)$ & 0.03 \\
DA >1.6 mm at 3 h & $44(67 \%)$ & $28(70 \%)$ & 0.7 \\
\hline
\end{tabular}

\section{RESULTS}

Cohort study. One hundred and twenty eight infants were enrolled. Measurements of LV function including $\mathrm{mVcfs}$ and LV wall stress were available for a total of 106 infants in the first $24 \mathrm{~h}$, including 94 at $3 \mathrm{~h}, 104$ at $10 \mathrm{~h}$, and 97 at $24 \mathrm{~h}$ (Table 1). Forty (42\%) of 106 infants developed low SVC flow in the first $24 \mathrm{~h}$. These infants were of significantly lower gestational age, and less likely to be growth restricted, born to mothers who had received antenatal steroids or were on antihypertensives. They were more likely to be transferred ex utero and to have a higher average MAP in the first $12 \mathrm{~h}$.

At $3 \mathrm{~h}$, there was a poor correlation (Pearson $r=0.15, p=$ 0.2 ) between mean BP and SVC flow, but a strong inverse correlation (Pearson $r=-0.90, p<0.001$ ) between the log of the calculated UBVR and SVC flow. At $3 \mathrm{~h}$ (Table 2), infants who developed low SVC flow in the first $24 \mathrm{~h}$ had a significantly lower mean BP, RVO, and SVC flow, and higher calculated UBVR $(0.649$ versus $0.414 \mathrm{~mm} \mathrm{Hg}$ per $\mathrm{mL} / \mathrm{kg} /$ $\mathrm{min})$. There was no significant difference in $\mathrm{mVcfs}$ or $\mathrm{LV}$ stress. However, infants who developed low SVC flow had significantly worse myocardial contractility as measured by the increased slope of the regression equation between LV stress and $\mathrm{mVcfs}(p=0.005)$ (Table 3, Fig. 1).

At $10 \mathrm{~h}$ (Table 2), 6 of 39 infants who developed low SVC flow in the first $24 \mathrm{~h}$ were on inotropes compared with 1 of 65 who maintained SVC flow. The infants who developed low SVC flow in the first $24 \mathrm{~h}$ had a significantly lower mean BP, larger diameter DA, and lower SVC flow and RVO at $10 \mathrm{~h}$. Calculated UBVR was significantly higher in the infants with low SVC flow (0.933 versus $0.509 \mathrm{~mm} \mathrm{Hg}$ per $\mathrm{mL} / \mathrm{kg} / \mathrm{min}$ ). There was no significant difference in $\mathrm{mVcfs}$ but a significantly lower LV stress (34.98 versus $42.16 \mathrm{~g} / \mathrm{cm}^{2}, p=0.02$ ). The difference in LV stress is similar in magnitude $(36.42$ versus $42.39 \mathrm{~g} / \mathrm{cm}^{2}$ ) but no longer significant if the six infants on inotropes are excluded. Myocardial contractility was no longer significantly different with the slope of the regression equation nearly identical $(p=0.06)$ (Table 3, Fig. 1).

At $24 \mathrm{~h}$ (Table 2), all 32 infants who developed low SVC flow were on inotropes with only 3 of these infants still having 
Table 2. Cardiorespiratory variables [mean (SD)] at 3, 10, and 24 in infants that maintained normal or had low SVC flow in the first $24 \mathrm{~h}$

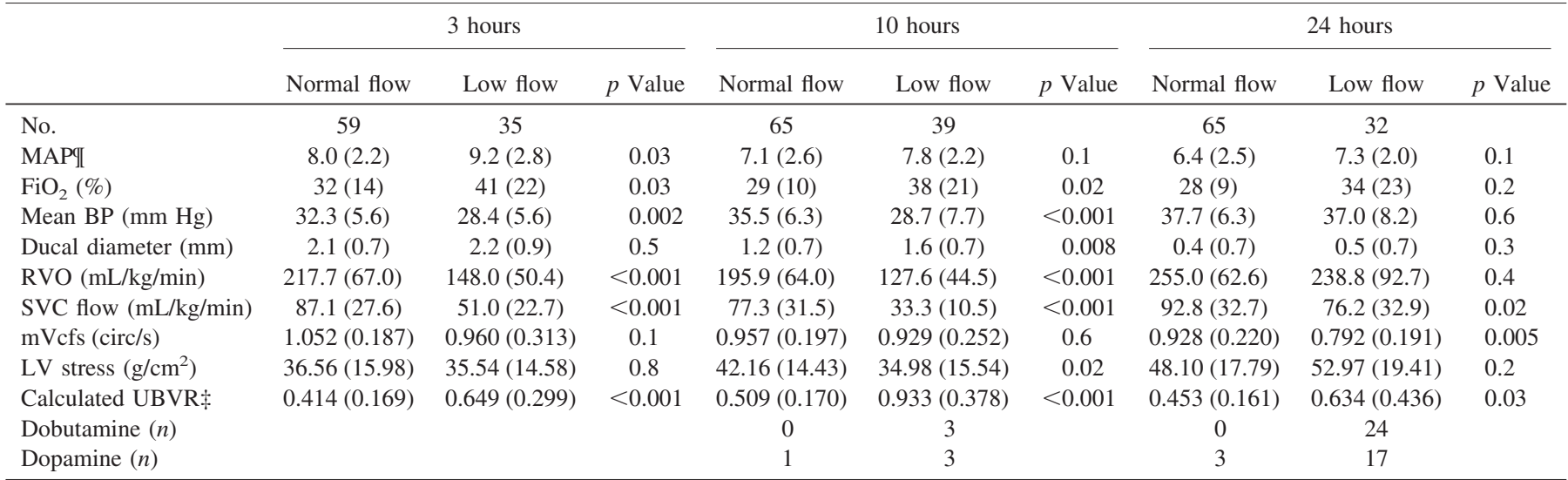

If $\mathrm{cm} \mathrm{H}_{2} \mathrm{O} ; \ddagger \mathrm{mm} \mathrm{Hg}$ per $\mathrm{mL} / \mathrm{kg} / \mathrm{min}$.

Table 3. Regression analyses of the relationship between mVcfs and LV wall stress in infants at 3, 10, and 24 h that maintained or had low SVC flow in the first $24 \mathrm{~h}$

\begin{tabular}{|c|c|c|c|c|c|}
\hline 3 hours & $\mathrm{mVcfs}(\mathrm{circ} / \mathrm{s})=$ & $n$ & $p$ Value & $r^{2}$ & $p$ Value (difference) \\
\hline Normal flow & $1.19-0.004 * \mathrm{LV}$ stress $\left(\mathrm{g} / \mathrm{cm}^{2}\right)$ & 59 & 0.004 & 0.13 & \\
\hline $\begin{array}{l}\text { Low flow } \\
10 \mathrm{~h}\end{array}$ & $1.46-0.014 *$ LV stress $\left(\mathrm{g} / \mathrm{cm}^{2}\right)$ & 35 & $<0.001$ & 0.43 & 0.005 \\
\hline $\begin{array}{l}\text { Low flow } \\
24 \mathrm{~h}\end{array}$ & $1.19-0.007 *$ LV stress $\left(\mathrm{g} / \mathrm{cm}^{2}\right)$ & 39 & 0.008 & 0.16 & 0.06 \\
\hline Normal flow & $1.18-0.005 * \mathrm{LV}$ stress $\left(\mathrm{g} / \mathrm{cm}^{2}\right)$ & 64 & $<0.001$ & 0.27 & \\
\hline
\end{tabular}
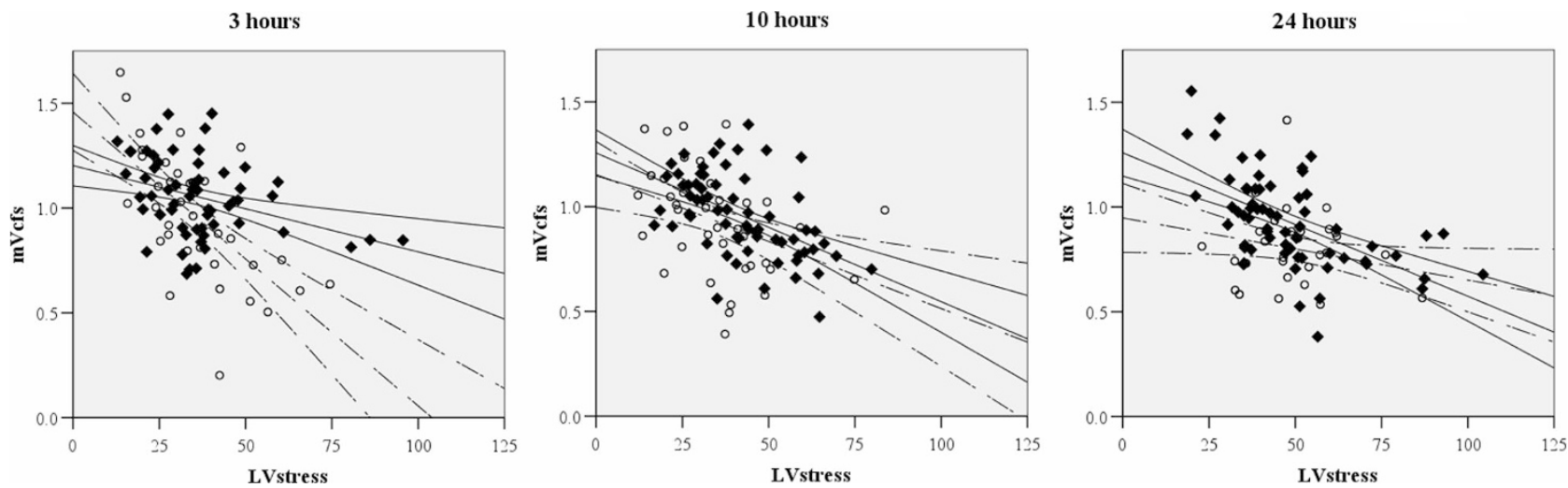

Figure 1. Myocardial contractility ( $\mathrm{mVcfs} v s \mathrm{LV}$ stress) at 3, 10, and $24 \mathrm{~h}$ in infants maintaining normal SVC flow $(\bullet)$ and developing low SVC flow $(\mathrm{O})$ in the first $24 \mathrm{~h}$. Regression lines (95\% confidence intervals) showing infants with low flow (dashed lines) had significantly worse contractility at $3 \mathrm{~h}$, but not 10 or $24 \mathrm{~h}$, compared with infants maintaining normal flows (solid lines).

low SVC flow. Three of 65 infants who had not developed low SVC flow were on inotropes for hypotension. Infants who developed low SVC flow in the first $24 \mathrm{~h}$ still had significantly lower SVC flow at this time but had similar mean BP. They had significantly lower $\mathrm{mVcfs}(0.792$ versus $0.928 \mathrm{circ} / \mathrm{s})$ but not significantly different LV stress. The calculated UBVR was significantly higher $\left(0.634\right.$ versus $\left.0.453 \mathrm{~g} / \mathrm{cm}^{2}\right)$. Myocardial contractility was significantly different although the slope of the regression equation was similar $(p=0.009)$ (Table 3, Fig. 1). The difference is due to a lower $\mathrm{mVcfs}$ than predicted for any given LV stress at this time in the infants who had developed low SVC flow.
Trial of dobutamine versus dopamine. Twenty-one infants randomized to volume and dobutamine and 16 infants to volume and dopamine had myocardial contractility measurements performed before and after a dose of $10 \mu \mathrm{g} / \mathrm{kg} / \mathrm{min}$ was reached. Ten infants randomized to dobutamine and 11 to dopamine had measurements before and after inotrope at a dose of $20 \mu \mathrm{g} / \mathrm{kg} / \mathrm{min}$. There were no significant differences between infants randomized to dobutamine and dopamine in baseline cardiorespiratory variables and measures of myocardial contractility (Table 4).

At $10 \mu \mathrm{g} / \mathrm{kg} / \mathrm{min}$, infants randomized to dobutamine had a reduction in calculated UBVR compared with an increase for 
Table 4. Baseline and change in cardiorespiratory variables [mean (SD)] before and after inotrope at 10 and $20 \mu \mathrm{g} / \mathrm{kg} / \mathrm{min}$

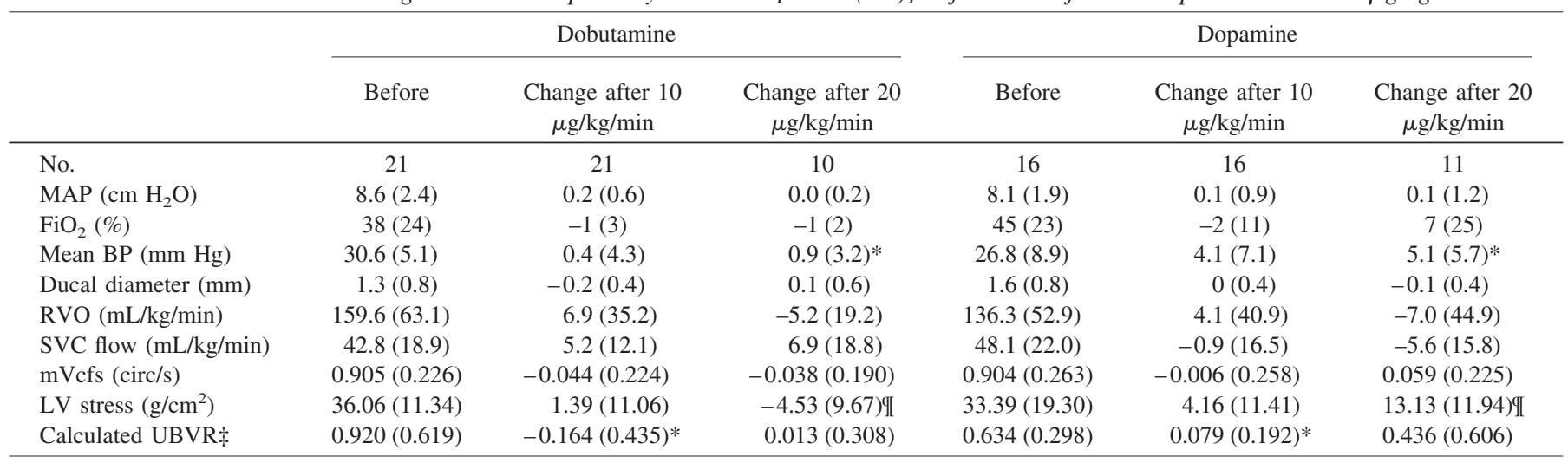

$* p<0.05 ; \rrbracket p<0.01 ;$ \$mm Hg per $\mathrm{mL} / \mathrm{kg} / \mathrm{min}$.

Table 5. Linear regression analyses of the relationship between $m V c f s$ and LV wall stress in infants before and after inotrope at 10 and $20 \mu \mathrm{g} / \mathrm{kg} / \mathrm{min}$

\begin{tabular}{|c|c|c|c|c|c|}
\hline Before inotrope & $\mathrm{mVcfs}(\mathrm{circ} / \mathrm{s})=$ & No. & $p$ Value & $r^{2}$ & $p$ Value (difference) \\
\hline Dobutamine & $1.57-0.018 * \mathrm{LV}$ stress $\left(\mathrm{g} / \mathrm{cm}^{2}\right)$ & 21 & $<0.001$ & 0.77 & \\
\hline Dopamine & $1.15-0.007 * \mathrm{LV}$ stress $\left(\mathrm{g} / \mathrm{cm}^{2}\right)$ & 16 & 0.09 & 0.20 & 0.8 \\
\hline \multicolumn{6}{|c|}{ Inotrope $10 \mu \mathrm{g} / \mathrm{kg} / \mathrm{min}$} \\
\hline Dopamine & $1.31-0.011 *$ LV stress $\left(\mathrm{g} / \mathrm{cm}^{2}\right)$ & 16 & $<0.001$ & 0.65 & 0.7 \\
\hline \multicolumn{6}{|c|}{ Inotrope $20 \mu \mathrm{g} / \mathrm{kg} / \mathrm{min}$} \\
\hline Dobutamine & $1.00-0.003 * \mathrm{LV}$ stress $\left(\mathrm{g} / \mathrm{cm}^{2}\right)$ & 10 & 0.1 & 0.29 & \\
\hline Dobutamine & $1.20-0.010 * \mathrm{LV}$ stress $\left(\mathrm{g} / \mathrm{cm}^{2}\right)$ & 21 & 0.002 & 0.23 & \\
\hline Dopamine & $1.26-0.010 * \mathrm{LV}$ stress $\left(\mathrm{g} / \mathrm{cm}^{2}\right)$ & 16 & 0.001 & 0.46 & 0.4 \\
\hline
\end{tabular}

infants randomized to dopamine, with the difference between inotropes being significant (Table 4). Changes in $\mathrm{mVcfs}$ and LV stress were not significantly different. In regression analysis of LV stress and mVcfs, there was no significant difference in myocardial contractility comparing dobutamine and dopamine at $10 \mu \mathrm{g} / \mathrm{kg} / \mathrm{min}$ (Table 5, Fig. 2). In addition, there was no significant difference between the regression equations for $\mathrm{mVcfs}$ and $\mathrm{LV}$ stress from before inotrope to after inotrope at $10 \mu \mathrm{g} / \mathrm{kg} / \mathrm{min}$ for either dobutamine or dopamine.

At $20 \mu \mathrm{g} / \mathrm{kg} / \mathrm{min}, 10$ infants randomized to dobutamine had a reduction in LV stress compared with an increase for 11 infants randomized to dopamine with the difference between inotropes being significant $\left(-4.53\right.$ versus $+13.13 \mathrm{~g} / \mathrm{cm}^{2}, p<$ 0.01) (Table 4). Changes in $\mathrm{mVcfs}$ and calculated UBVR were not significantly different (Table 4). In regression analysis of LV stress and mVcfs (Table 5, Fig. 2), there was a significant difference in myocardial contractility between infants on dobutamine and infants on dopamine $(p=0.02)$. These findings were not affected by adjusting for gestational age, a complete course of antenatal corticosteroids, and baseline MAP and SVC flow.

An analysis of myocardial contractility at the highest dose reached included all infants (Table 5). At the highest dose of inotrope reached (10 or $20 \mu \mathrm{g} / \mathrm{kg} / \mathrm{min}$ ), there was no significant difference $(p=0.4)$ in myocardial contractility (relationship between $\mathrm{mVcfs}$ and LV stress) between infants receiving dobutamine or dopamine (Fig. 2).

Dopamine versus dobutamine: combined regression anal$y$ sis- $\boldsymbol{m} V \boldsymbol{V} f \mathbf{s}$ versus $\boldsymbol{L} \boldsymbol{V}$ Stress. Using the combined regres-
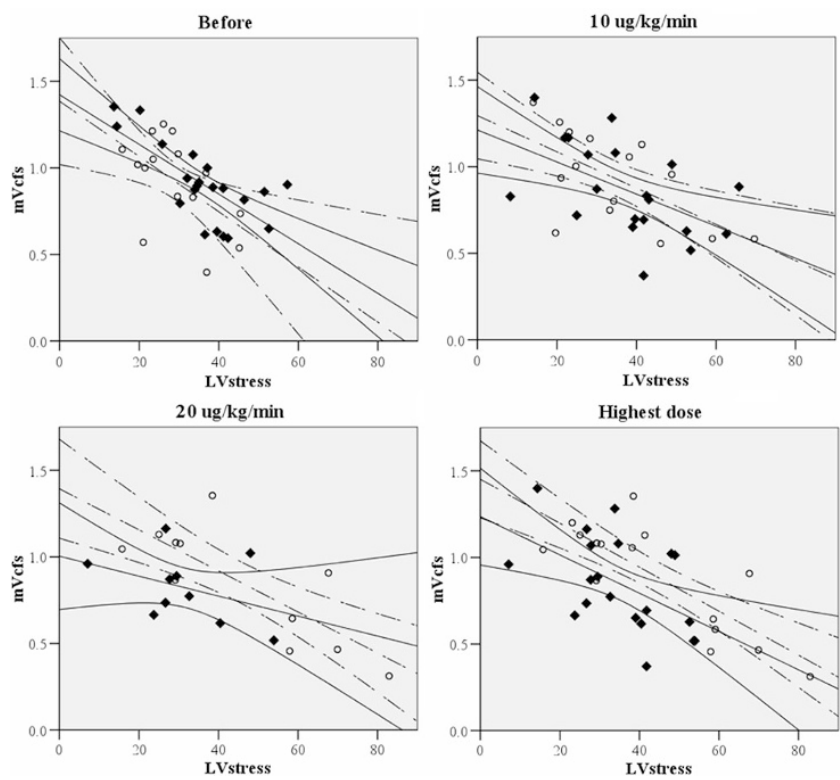

Figure 2. Regression lines (95\% confidence intervals) demonstrating relationship between $\mathrm{mVcfs}$ and LV stress for infants receiving dobutamine $(\diamond$, solid lines) and dopamine $(\bigcirc$, dashed lines $)$ at 0,10 , and $20 \mu \mathrm{g} / \mathrm{kg} / \mathrm{min}$, and the highest dose reached.

sion model described in methods, there was no significant difference between inotrope groups before infusion (difference between inotropes $=-0.055 \mathrm{circ} / \mathrm{s}, \mathrm{SE}=0.073, p=0.5$ ) or at $10 \mu \mathrm{g} / \mathrm{kg} / \mathrm{min}$ (difference $=0.092 \mathrm{circ} / \mathrm{s}, \mathrm{SE}=0.083, p=$ 0.3 ), but there was a significant difference at $20 \mu \mathrm{g} / \mathrm{kg} / \mathrm{min}$ 
(difference $=0.231 \mathrm{circ} / \mathrm{s}, \mathrm{SE}=0.105, p=0.03$ ). The slope was constant across all time periods, and was estimated to be $\mathrm{mVcfs}=-0.00981 * \mathrm{LV}$ stress $(\mathrm{SE}=0.00176, p<0.0001)$. Hence, the expected value of $\mathrm{mVcfs}$ decreases $0.00981 \mathrm{circ} / \mathrm{s}$ per $1 \mathrm{~g} / \mathrm{cm}^{2}$ increase in LV stress. The difference between inotropes at $20 \mu \mathrm{g} / \mathrm{kg} / \mathrm{min}$ is due to a reduction in expected $\mathrm{mVcfs}$ in infants on dobutamine for any given LV stress compared with infants on dopamine. These findings were not affected by adjusting for gestational age, a complete course of antenatal corticosteroids, and baseline MAP and SVC flow.

\section{DISCUSSION}

This study has shown that infants who develop low SBF in the first day have significantly worse LV contractility in response to higher wall stress. We have previously reported that very premature infants are at high risk of developing low SBF in the first $24 \mathrm{~h}(1,2,13)$. To overcome the problem of shunts across the adapting heart confounding ventricular outputs as a measure of $\operatorname{SBF}(13,14,17)$, we have used SVC flow as a measure of upper body and brain blood flow that is not affected by these shunts $(1,12)$. Low SVC flow was a consistent and significant risk factor for infants developing late peri/intraventricular hemorrhage, neonatal mortality $(1,2)$ and subsequent neurodevelopmental impairments (3). These low SVC flows were associated with lower gestation age at birth, higher MAP, and larger diameter DA in the first hours, as well as a high calculated UBVR $(1,2)$. However, it has been unclear as to whether the higher calculated UBVR is a compensatory mechanism for low SBF to maintain blood flow to vital organs ("compensated shock"), or whether the increased vascular resistance is a contributory factor with high vascular resistance leading to low cardiac output and organ blood flow in extremely premature infants with poor myocardial contractility. For this reason, in this study we decided to use direct preload independent measures of myocardial contractility that account for afterload to directly measure the response of the left ventricle to varying after-loads in a population of infants, many of who developed low SBF as measured by SVC flow. It has previously been reported that preterm infants have lower myocardial contractility than term infants at $6 \mathrm{~h}$ of age (9). However, the relationship to SBF and response to inotropes has not been reported in extremely preterm infants.

Infants who developed low SVC flow in the first $24 \mathrm{~h}$ had significantly worse myocardial contractility at $3 \mathrm{~h}$ of age as measured by an increased negative slope of relationship between $\mathrm{mVcfs}$ and LV stress. This was despite there being no significant difference in the average $\mathrm{mVcfs}$ and average $\mathrm{LV}$ stress between infants with and without low flow. This strongly suggests that the problem in extremely premature infants who develop low flow is inability to maintain left ventricular velocity of contraction against the increased afterload found in the early postnatal period. High systemic vascular resistance may be a compensatory mechanism for low SBF, but the presence of poor myocardial contractility at $3 \mathrm{~h}$ before many developed low flow suggests it is also a contributing factor. The difference in myocardial contractility was also significant at $24 \mathrm{~h}$, but did not reach significance at $10 \mathrm{~h}$.
The relationship is confounded at these times by the use of inotropes and the potential for myocardial adaptation over time. At $3 \mathrm{~h}$, low-flow infants had a greater than expected reduction in $\mathrm{mV}$ cfs as $\mathrm{LV}$ stress increased (i.e. increased slope of the regression line). However, by $24 \mathrm{~h}$ the difference in contractility is associated with a lower than expected $\mathrm{mVcfs}$ at all levels of LV stress (change in position of regression line). This suggests there has been a global deterioration in myocardial function over time in infants with low SVC flow. This may reflect myocardial immaturity (18-20) or injury.

We have previously reported that over $40 \%$ of infants with low SVC flow failed to respond or maintain SVC flow on either dopamine (32\%) or dobutamine (55\%) (11). The use of inotropes did not change the slope of the relationship between $\mathrm{mVcfs}$ and LV stress at 10 or $20 \mu \mathrm{g} / \mathrm{kg} / \mathrm{min}$. At $20 \mu \mathrm{g} / \mathrm{kg} / \mathrm{min}$ there was evidence that the expected $\mathrm{mVcfs}$ for any given $\mathrm{LV}$ stress was lower for infants on dobutamine, but this analysis is restricted to 21 infants with persisting low SVC flow who progressed to the higher dose. When infants were compared at the highest dose reached, there was again no difference in myocardial contractility between infants on dobutamine or dopamine. Of note is that there was no improvement in myocardial contractility in infants on either inotrope, with trends to deterioration at increasing dose. In addition, dobutamine produced a significant decrease in calculated UBVR at a dose of 10 $\mu \mathrm{g} / \mathrm{kg} / \mathrm{min}$, whereas dopamine produced a significant increase in LV stress at $20 \mu \mathrm{g} / \mathrm{kg} / \mathrm{min}$. At this dose, there was a trend to falling SVC flow. These were short-term assessments of the effects of inotropes on flow and contractility. At $24 \mathrm{~h}$, infants on dobutamine had a significantly greater RVO than infants on dopamine (11). Further research is needed to determine whether treating hypotension with higher doses of dopamine is safe over the first day, or whether this strategy will lead to a subsequent reduction in systemic and organ blood flows due to poor myocardial contractility resulting in "decompensated" shock.

Methodological strengths of this study include the relatively large sample size for an echocardiographic study in preterm infants, measurements of myocardial contractility at $3 \mathrm{~h}$ preceded the development of low SVC flow for most infants, and inotrope interventions were blinded by use of identically labeled syringes resulting in contractility measurements being blinded to treatment allocation. However, not all infants randomized to inotrope had the dose increased to $20 \mu \mathrm{g} / \mathrm{kg} / \mathrm{min}$ making these observations potentially biased. We have exercised caution in interpreting differences in effect at this dose although adjusting this analysis for risk factors for nonresponse (lower gestation, incomplete antenatal steroids, baseline MAP and SVC flow) did not affect this conclusion. Infants had echocardiographic measurements $30 \mathrm{~min}$ after change of dose of inotrope. We speculate that substantially increasing LV stress in extremely premature infants in the first day is likely to result in substantial falls in systemic and organ blood flows. Further blinded, randomized studies are needed to determine the effect of inotropes over the first day. Finally, measurements of LV dimensions in extremely premature infants are difficult, although intra- and interobserver reliability have previously been reported to be good. Intra- and interob- 
server reliability could not be conducted in the context of this interventional study given the small size of the infants and the frequency of echocardiography. The substantial variability in measurements is evidenced in the scatter plots of $\mathrm{mVcfs}$ versus LV stress (Figs. 1 and 2) and the wide standard deviations for mVcfs and LV stress (Table 2 and Table 4). This variability will include both substantial between infant variability and measurement error. Difficulties with measurement include the elliptical shape of the extremely preterm infant left ventricle and variability of LV topography impacting on accuracy of tracings of LV circumferential dimensions and wall thickness. The differences in contractility between infants with low and normal flows are unlikely to be biased by measurement. However, important differences between inotropes may not have been detected by measurements with substantial variability.

Identification of the mechanisms of low SBF in extremely preterm infants in the first day offers a therapeutic opportunity. Infants who develop low SVC flow are born more immature, ventilated with higher MAP $(1,2,13)$ and have a larger diameter DA $(1,21)$ in the first hours. They have higher systemic $(1,2)$ and pulmonary $(13)$ vascular resistances and poor myocardial contractility. Many do not respond to inotropes (11), with no improvement in myocardial contractility observed with either inotrope in this study, suggesting an immaturity of the extremely preterm infant's myocardium (18). Infants that fail to respond are less likely to have received a complete course of antenatal steroids (11). Potential therapeutic options are limited with a need to identify antenatal strategies for maturing the infant's myocardium, postnatal strategies to reduce the effect of ventilatory management on SBF, and the use of cardiovascular treatments to prevent low SBF. We are currently studying the effect of milrinone (a phosphodiesterase inhibitor with "inodilator" properties) with the goal of preventing SBF (22), given that milrinone has been used to treat (23) and prevent (24) low cardiac output syndrome after cardiac surgery, a condition that shares many of the hemodynamic features with that found in the extremely premature infant in the first day.

In conclusion, infants who develop low SVC flow in the first day have significantly worse myocardial contractility. Neither dopamine nor dobutamine produces an improvement in myocardial contractility in preterm infants in the first day after birth. At $20 \mu \mathrm{g} / \mathrm{kg} / \mathrm{min}$, dopamine substantially increases LV afterload. Further research is required to validate the accuracy of these measurements of myocardial contractility in preterm infants, and to reproduce these findings in another preterm infant population with low SBF.
Acknowledgments. The authors thank Petra Macaskill (Department of Public Health, University of Sydney) for her assistance with the regression analysis of the effect of inotropes on contractility.

\section{REFERENCES}

1. Kluckow M, Evans N 2000 Low superior vena cava flow and intraventricular haemorrhage in preterm infants. Arch Dis Child Fetal Neonatal Ed 82:F188-F194 2. Osborn DA, Evans N, Kluckow M 2003 Hemodynamic and antecedent risk factors of early and late periventricular/intraventricular hemorrhage in premature infants. Pediatrics 112:33-39

3. Hunt RW, Evans N, Rieger I, Kluckow M 2004 Low superior vena cava flow and neurodevelopment at 3 years in very preterm infants. J Pediatr 145:588-592

4. Colan SD, Borow KM, Neumann A 1984 Left ventricular end-systolic wall stressvelocity of fiber shortening relation: a load-independent index of myocardial contractility. J Am Coll Cardiol 4:715-724

5. Lang RM, Borow KM, Neumann A, Janzen D 1986 Systemic vascular resistance: an unreliable index of left ventricular afterload. Circulation 74:1114-1123

6. Gill AB, Weindling AM 1993 Echocardiographic assessment of cardiac function in shocked very low birthweight infants. Arch Dis Child 68:17-21

7. Harada K, Shiota T, Takahashi Y, Tamura M, Takada G 1994 Changes in the volume and performance of the left ventricle in the early neonatal period. Early Hum Dev 39:201-209

8. Takahashi Y, Harada K, Shiota T, Tamura M, Noguchi H, Ishida A, Takada G 1994 Left ventricular contractile state of early human neonates with patent ductus arteriosus. Tohoku J Exp Med 172:155-161

9. Takahashi Y, Harada K, Kishkurno S, Arai H, Ishida A, Takada G 1997 Postnatal left ventricular contractility in very low birth weight infants. Pediatr Cardiol 18:112-117

10. Osborn DA, Evans N, Kluckow M 2003 Effect of early targeted indomethacin on the ductus arteriosus and blood flow to the upper body and brain in the preterm infant. Arch Dis Child Fetal Neonatal Ed 88:F477-F482

11. Osborn D, Evans N, Kluckow M 2002 Randomized trial of dobutamine versus dopamine in preterm infants with low systemic blood flow. J Pediatr 140:183-191

12. Kluckow M, Evans N 2000 Superior vena cava flow in newborn infants: a novel marker of systemic blood flow. Arch Dis Child Fetal Neonatal Ed 82:F182-F187

13. Evans N, Kluckow M 1996 Early determinants of right and left ventricular output in ventilated preterm infants. Arch Dis Child Fetal Neonatal Ed 74:F88-F94

14. Evans N, Iyer P 1994 Assessment of ductus arteriosus shunt in preterm infants supported by mechanical ventilation: effect of interatrial shunting. J Pediatr 125:778-785

15. Berdjis F, Takahashi M, Lewis AB 1992 Left ventricular performance in neonates on extracorporeal membrane oxygenation. Pediatr Cardiol 13:141-145

16. Grossman W, Jones D, McLaurin LP 1975 Wall stress and patterns of hypertrophy in the human left ventricle. J Clin Invest 56:56-64

17. Evans N, Iyer P 1994 Incompetence of the foramen ovale in preterm infants supported by mechanical ventilation. J Pediatr 125:786-792

18. Seri I 2005 Inotrope, lusitrope, and pressor use in neonates. J Perinatol 25:S28-S30

19. Friedman WF 1972 The intrinsic physiologic properties of the developing heart Prog Cardiovasc Dis 15:87-111

20. Sheldon CA, Friedman WF, Sybers HD 1976 Scanning electron microscopy of fetal and neonatal lamb cardiac cells. J Mol Cell Cardiol 8:853-862

21. Evans N, Kluckow M 1996 Early ductal shunting and intraventricular haemorrhage in ventilated preterm infants. Arch Dis Child Fetal Neonatal Ed 75:F183-F186

22. Paradisis M, Evans N, Kluckow M, Osborn D, McLachlan AJ 2006 Pilot study of milrinone for low systemic blood flow in very preterm infants. J Pediatr 148:306-313

23. Chang AC, Atz AM, Wernovsky G, Burke RP, Wessel DL 1995 Milrinone: systemic and pulmonary hemodynamic effects in neonates after cardiac surgery. Crit Care Med 23:1907-1914

24. Hoffman TM, Wernovsky G, Atz AM, Kulik TJ, Nelson DP, Chang AC, Bailey JM, Akbary A, Kocsis JF, Kaczmarek R, Spray TL, Wessel DL 2003 Efficacy and safety of milrinone in preventing low cardiac output syndrome in infants and children after corrective surgery for congenital heart disease. Circulation 107:996-1002 